\title{
Donor-site morbidity after osteochondral autologous transplantation for osteochondritis dissecans of the capitellum: a systematic review and meta-analysis
}

\author{
Rens Bexkens $^{1,2}$ (1) • Paul T. Ogink ${ }^{1} \cdot$ Job N. Doornberg $^{2} \cdot$ Gino M. M. J. Kerkhoffs $^{2,3,4}$ • \\ Denise Eygendaal $^{2,5} \cdot$ Luke S. Oh$^{1} \cdot$ Michel P. J. van den Bekerom ${ }^{6}$
}

Received: 16 November 2016 / Accepted: 6 March 2017 / Published online: 8 April 2017

(c) The Author(s) 2017. This article is an open access publication

\begin{abstract}
Purpose To determine the rate of donor-site morbidity after osteochondral autologous transplantation (OATS) for capitellar osteochondritis dissecans.

Methods A literature search was performed in PubMed/ MEDLINE, Embase, and Cochrane Library to identify studies up to November 6, 2016. Criteria for inclusion were OATS for capitellar osteochondritis dissecans, reported outcomes related to donor sites, $\geq 10$ patients, $\geq 1$ year follow-up, and written in English. Donor-site morbidity was defined as persistent symptoms $(\geq 1$ year) or cases that required subsequent intervention. Patient and harvest characteristics were described, as well as the rate of donor-site morbidity. A random effects model was used to calculate and compare weighted group proportions.
\end{abstract}

Electronic supplementary material The online version of this article (doi:10.1007/s00167-017-4516-8) contains supplementary material, which is available to authorized users.

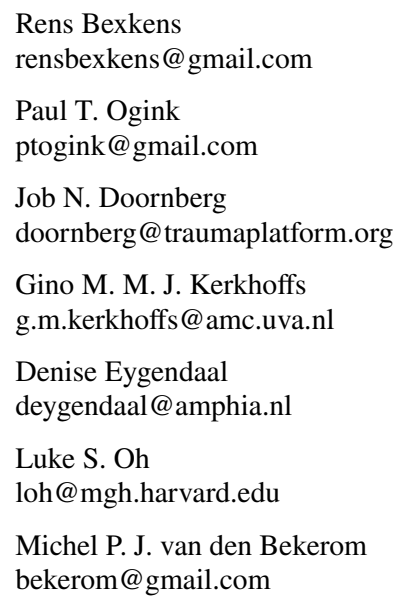

Results Eleven studies including 190 patients were included. In eight studies, grafts were harvested from the femoral condyle, in three studies, from either the 5th or 6th costal-osteochondral junction. The average number of grafts was 2 (1-5); graft diameter ranged from 2.6 to $11 \mathrm{~mm}$. In the knee-to-elbow group, donor-site morbidity was reported in 10 of 128 patients (7.8\%), knee pain during activity (7.0\%) and locking sensations $(0.8 \%)$. In the rib-to-elbow group, one of 62 cases $(1.6 \%)$ was complicated, a pneumothorax. The proportion in the knee-to-elbow group was 0.04 (95\% CI $0.0-0.15$ ), and the proportion in the rib-to-elbow group was 0.01 (95\% CI 0.00-0.06). There were no significant differences between both harvest techniques (n.s.).

Conclusions Donor-site morbidity after OATS for capitellar osteochondritis dissecans was reported in a considerable group of patients.

Level of evidence Level IV, systematic review of level IV studies.

1 Department of Orthopaedic Surgery, Sports Medicine Service, Massachusetts General Hospital, Harvard Medical School, 175 Cambridge Street, Boston, MA 02114, USA

2 Department of Orthopaedic Surgery, Academic Medical Center, University of Amsterdam, Meibergdreef 9, 1105 AZ Amsterdam, The Netherlands

3 Academic Center for Evidence based Sports medicine (ACES), Amsterdam, The Netherlands

4 Amsterdam Collaboration for Health and Safety in Sports (ACHSS), AMC/VUmc IOC Research Center, Amsterdam, The Netherlands

5 Department of Orthopaedic Surgery, Amphia Hospital, Molengracht 21, 4818 CK Breda, The Netherlands

6 Department of Orthopaedic Surgery, Shoulder and Elbow Unit, Onze Lieve Vrouwe Gasthuis, Oosterpark 9, 1091 AC, Amsterdam, The Netherlands 
Keywords Osteochondritis dissecans · Capitellum · Graft harvesting - Osteochondral autologous transplantation . Knee $\cdot$ Donor-site morbidity.

\section{Introduction}

Osteochondritis dissecans (OCD) of the capitellum is a disorder of the subchondral bone and articular cartilage $[3,23,32]$. This condition is primarily seen in teenagers engaged in sporting activities in which the elbow is repetitively exposed to extensive valgus forces, such as baseball and gymnastics [3, 23, 32]. In early phases, a stable capitellar OCD may cause pain and effusion, while in advanced stages, the OCD may become unstable and cause locking, restricted range of motion, and instability [3, 23, 32]. Stable OCD may initially be treated nonoperatively with activity modification and physical therapy [17, 18], whereas unstable lesions require operative treatment. Several surgical options have been developed over the past two decades including arthroscopic debridement with or without marrow stimulation [13, 26, 29], fragment fixation [7, 10, 31], and osteochondral autologous transplantation (OATS) [15, $16,24,33]$.

OATS has become a popular treatment option for large, unstable lesions (diameter $>10 \mathrm{~mm}$ ) with lateral wall involvement, as well as also for athletes without an acceptable outcome after less invasive techniques [8, 15, 22, 24]. In OATS, a single or multiple osteochondral grafts are harvested from either the less-weight-bearing parts of the femoral condyle $[8,11,15,24]$ or the costal-osteochondral junction $[22,30]$. The cylindrical donor plug consisting of hyaline cartilage and subchondral bone is then transplanted into the defect area to restore the integrity of the articular surface of the capitellum. A major disadvantage of this procedure is the need to harvest one or multiple grafts from an asymptomatic knee or the rib area in an adolescent athlete and thus the risk for morbidity at the donor site $[2,12,27]$. Recently, a review conducted by Andrade et al. reported knee donor-site morbidity rates of $17 \%$ and $6 \%$ for ankle and knee mosaicplasty procedures, respectively [2]. In contrast, two studies involving adolescent athletes who underwent OATS for OCD of the capitellum found no adverse effects related to the donor site [9, 35]. Interestingly, Weigelt et al. reported substantial donor-site morbidity in eight of 14 patients treated for capitellar OCD [33]. The vast majority of patients with capitellar OCD are high-demand athletes who are younger than patients with knee and ankle OCD [2,9]. Also, as opposed to knee and ankle OCD, grafts have been harvested from both the femoral condyle and costal-osteochondral junction in the treatment of capitellar OCD [9, 30]. Knowing the overall risk for donor-site morbidity following capitellar OATS is relevant in surgical decision making, as well as it is essential to be able to counsel patients about the risk for possible donor-site effects. To our knowledge, the risk of donor-site morbidity after OATS in this particular population is still unknown.

The purpose of this study was to determine the rate of donor-site morbidity following osteochondral autologous transplantation for capitellar osteochondritis dissecans. The hypothesis op the study was that there would be no difference in the proportion of donor-site morbidity between graft harvesting from the femoral condyle or costal-osteochondral junction.

\section{Materials and methods}

\section{Protocol}

The findings of this systematic review were reported according to the Preferred Reporting Items for Systematic Review and Meta-Analyses (PRISMA) guidelines [14].

\section{Selection criteria}

Studies that met the following inclusion criteria were included: (1) osteochondral autologous transplantation for capitellar OCD, (2) reported outcomes related to the donor site, (3) minimum inclusion of 10 patients, (4) minimum follow-up of one year, and (5) written in English. Case reports, reviews, and cadaveric studies were excluded. Donor-site morbidity was defined as the presence of persistent symptoms ( $\geq 1$ year) after graft harvesting, as well as the need for subsequent intervention to treat complications related to the donor site.

\section{Search strategy}

A literature search was performed in the following databases up to November 6, 2016: PubMed/MEDLINE, Embase, and the Cochrane Library. The PubMed/MEDLINE search strategy was adjusted into similar search strategies for other databases (Online Appendix 1). Reference lists of retrieved studies were manually searched for additional studies potentially meeting the inclusion criteria.

\section{Study selection}

Study selection was independently performed by two authors. First, title and abstract were screened to identify potentially relevant papers (R.B. and P.O.). These results were verified by two senior authors (L.O. and M.v.d.B.). Subsequently, manuscripts were retrieved when title or abstract revealed insufficient information to determine the 
appropriateness for inclusion. Disagreement was resolved by discussion or with arbitration when necessary by the senior authors (L.O. and M.v.d.B.) when differences remained.

\section{Data extraction}

The main outcome of interest was the presence or absence of donor-site morbidity (persistent symptoms or need for subsequent intervention) after capitellar OATS. The following data were extracted from each study: author names, year of publication, patient demographics, follow-up time, harvest method, graft characteristics, and the use of fillers. The following outcomes related to the donor site were extracted: symptoms (e.g., pain, locking, and instability), physical examination (e.g., effusion and range of motion), complications (e.g., infection, nerve injury, or subsequent treatment), patient reported outcome scores, imaging evaluation [e.g., radiographs, computed tomography, or magnetic resonance imaging (MRI)], and anatomic and histological outcomes. Data extraction was independently performed by two authors (R.B. and P.O.) and verified by two senior authors (L.O. and M.v.d.B.). Articles were not blinded for author, affiliation, and source.

\section{Methodological quality assessment}

Two authors (R.B. and P.O.) independently judged the methodological quality of included studies using the checklist for quality appraisal of case series studies that was developed at the Institute of Health Economics (IHE) [5, 20]. Each of the 20 criteria of the checklist were answered with either 'yes,' 'no,' or 'partial' or 'unclear.' For estimating the risk of bias for each study, 'partial' responses were considered 'yes,' and 'unclear' responses were considered 'no.' A study with 0-2 'no' responses was considered to have a low risk of bias, 3-5 'no' responses a moderate risk, 6-8 'no' responses a high risk, and 9 or more 'no' responses a very high risk of bias. In case of disagreement, two senior authors (L.O. and M.v.d.B.) were involved to solve the differences.

\section{Statistical analysis}

Categorical data were displayed as absolute numbers with frequencies; continuous data were displayed as means with sample range.

The main outcomes of interest were the rate of donorsite morbidity within the knee-to-elbow group and rib-toelbow group. Proportions of donor-site morbidity were calculated for each study using the Freeman-Tukey double arcsine transformation. Subsequently, a random effects model, to account for heterogeneity across studies, was used to calculate weighted group proportions for each harvest technique, and to compare proportions between the two techniques [19, 34]. A $p$ value $<0.05$ was considered significant. Statistical analyses were performed with the use of Stata 13.0 (College Station, TX, USA).

\section{Results}

\section{Population and harvest characteristics}

A detailed summary of patient and harvest characteristics for each study is given in Table 1. A total of 11 studies including 190 patients met the criteria after careful systematic selection (Fig. 1) [9, 11, 15, 16, 21, 22, 24, 28, 30, 33, 35]. The mean age across the selected studies was 15 years (range, 14-18), and the mean follow-up length was 37 months (range, 22-84).

The knee served as the donor site in 128 patients across eight studies (Table 1) [9, 11, 15, 16, 21, 24, 33, 35]. The average number of grafts harvested was 2 (range 1-5) $[9,16,21,33,35]$, and graft diameter ranged from 2.6

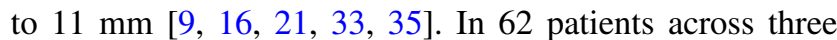
studies, either the 5th or 6th costal-osteochondral junction served as the harvest site [22, 28, 30]. Either one or two grafts were harvested for each patient $[22,28,30]$.

\section{Donor-site morbidity}

A detailed summary of donor-site effects per study is given in Table 2. In the knee-to-elbow group, donor-site morbidity after capitellar OATS was reported in 10 of 128 patients, resulting in a donor-site morbidity rate of $7.8 \%$. Knee pain while stair climbing and heavy lifting were reported in nine patients $(7.0 \%)$ and locking sensations in one patient $(0.8 \%)$ (Table 2) [9, 16, 33]. In the rib-to-elbow group, donor-site morbidity was reported in one of 62 patients, resulting in a donor-site morbidity rate of $1.6 \%$. One case was complicated by a pneumothorax due to damage to the costal pleura, which required insertion of a chest tube [30].

The proportion of donor-site morbidity in the knee-toelbow group was 0.04 (95\% CI $0.0-0.15$ ), and the proportion in the rib-to-elbow group was 0.01 (95\% CI 0.00-0.06) (Fig. 2). There was no significant difference between the two harvest techniques in terms of proportion of donor-site morbidity $(p>0.05)$.

\section{Methodological quality}

The results of methodological quality assessment of individual studies using the IHE scale are presented in Table 3. According to the criteria of the IHE checklist for critical appraisal of case series studies, the estimated potential 


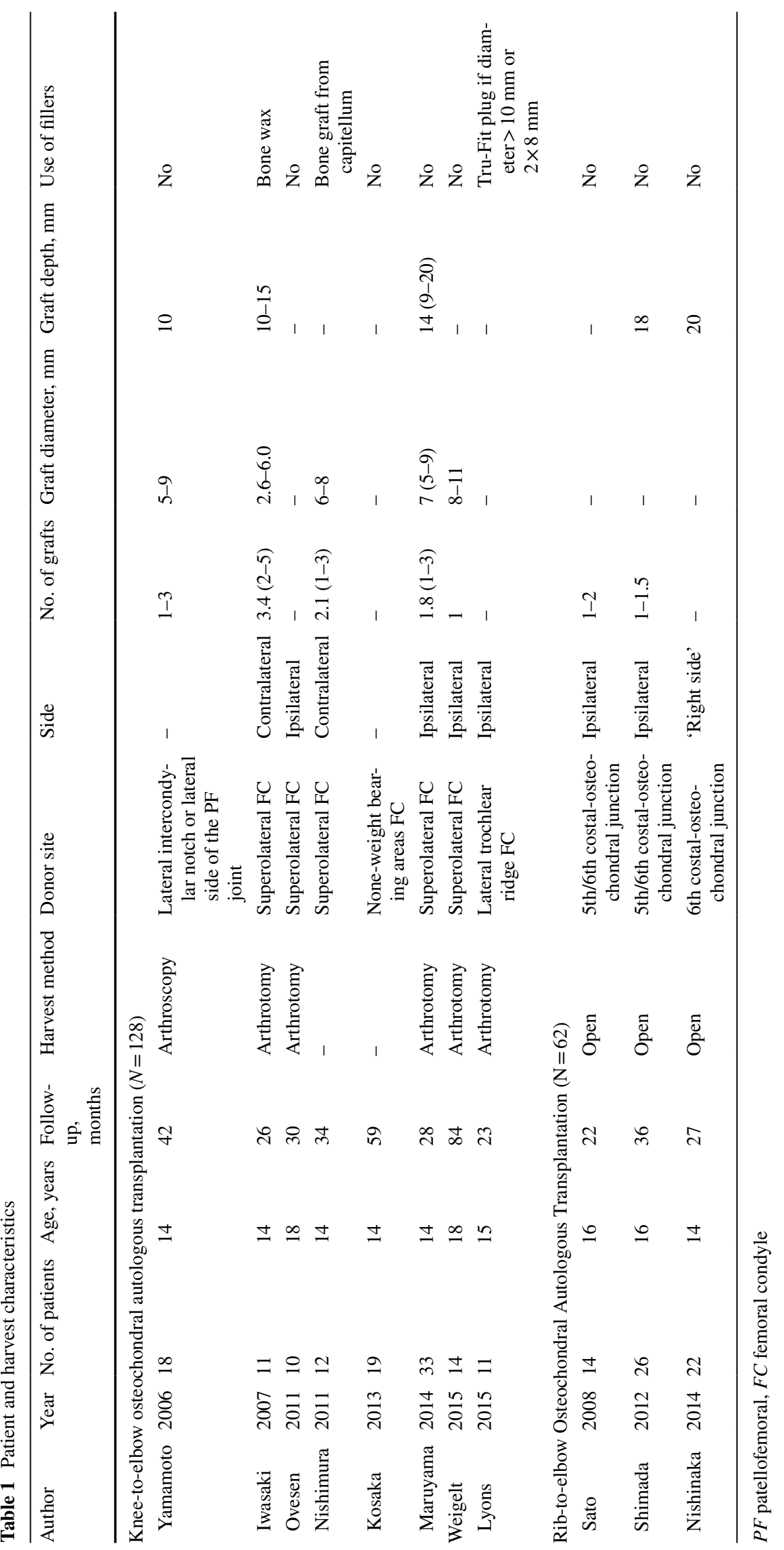


Fig. 1 Flowchart of search strategy following PRISMA (preferred reporting items for systematic reviews and metaanalyses) guidelines

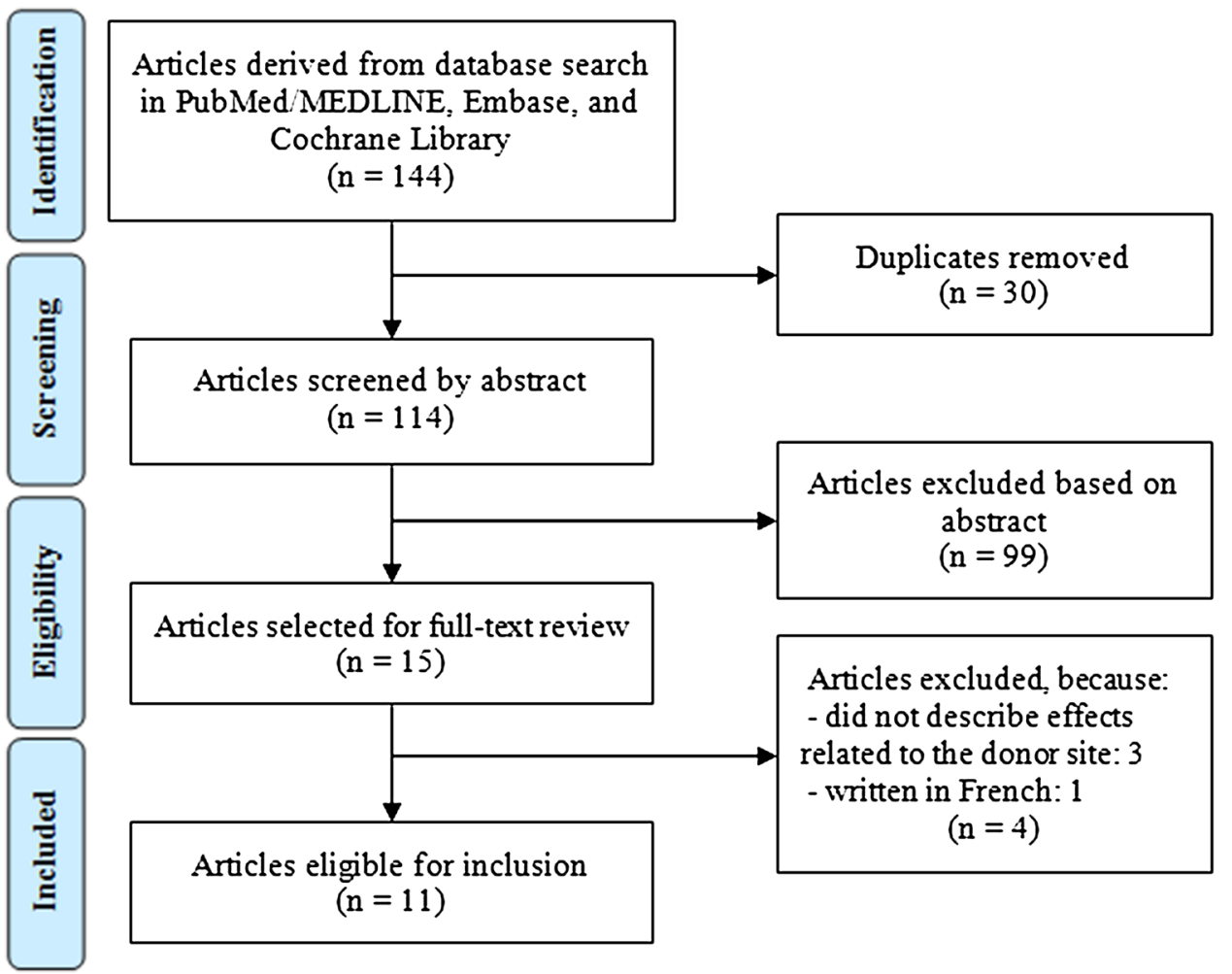

risk of bias was low for one study [21], moderate for nine studies [9, 11, 15, 16, 22, 24, 30, 33, 35], and high for one study [28]. Solely 'no' responses were awarded to question 3 and 11, which are related to the patient recruitment process and blinding of outcome assessors, respectively. Here, no study recruited patients from multiple centers, nor was outcome assessment blinded. Three more questions, also related to outcome measures (10, measures established a priori; 12, appropriateness of measures; 13, before and after intervention measured), were awarded with 'no' or 'partial' responses in more than half of the included studies. By contrast, most criteria with regard to the study aim (question 1), study population (question 5-7), intervention (question 8), statistical analysis (question 14), results/conclusions (question 15-19), and sources of support (question 20) were awarded a 'yes' response.

\section{Discussion}

The most important finding of the present study is that donor-site morbidity after osteochondral autologous transplantation for capitellar osteochondritis dissecans occurred in $7.8 \%$ within the knee-to-elbow group and $1.6 \%$ within the rib-to-elbow group. In the knee-to-elbow group, knee pain during daily activities (7.0\%) and locking sensations $(0.8 \%)$ were reported; in the rib-to-elbow group, one case was complicated by a pneumothorax. There was no significant difference in proportion of donor-site morbidity between the two harvest techniques. The findings of this systematic review emphasize the importance of associated donor-site morbidity following graft harvesting in the treatment of capitellar OCD.

The rate of donor-site morbidity in our study is comparable to the morbidity rate after knee-to-knee OATS (6\%), as reported by Andrade et al. [2]. Interestingly, the authors reported a higher rate after knee-to-ankle OATS (17\%) [32]. The higher rate compared to our findings may be the result of more grafts that were harvested (three versus two) [2], although the influence of the number of grafts on morbidity is controversial [1, 2, 25, 27]. Patient characteristics may have played a role as well. The vast majority of patients in our study were adolescent (15 years), highdemanding athletes, while patients with talar OCD are typically older (32 years [25]). We hypothesized that patients in our study may have been in a better physical condition before treatment, and therefore faster recovery with less donor-site effects may be expected.

In the present study, the rate of donor-site morbidity ranged from 0 to $57 \%$ in studies in whom grafts were harvested from the knee. Weigelt et al. reported morbidity in eight of 14 patients (57\%): occasional pain during heavy lifting in seven patients and intermittent locking sensations in one patient [33]. The advanced age after a relative long follow-up ( 7 years) may be the reason for more morbidity, as well as it may be the result of large grafts $(8-11 \mathrm{~mm})$ 
Table 2 Donor-site effects after osteochondral autologous transplantation for capitellar osteochondritis dissecans

\begin{tabular}{|c|c|c|c|c|}
\hline Author & Complications & Physical examination & Patient reported outcomes & Imaging \\
\hline \multicolumn{5}{|c|}{ Knee-to-elbow osteochondral autologous transplantation $(N=128)$} \\
\hline Yamamoto & No & No effusion & No pain & - \\
\hline Iwasaki & No & $\begin{array}{l}\text { Effusion up to } 5 \text { weeks in } 8 \text { pts } \\
\text { (mean: } 3 \text { weeks); full range of } \\
\text { motion; thigh and calf girth } \\
100 \%\end{array}$ & $\begin{array}{l}\text { Lysholm } 99.6 \text { (range } 96-100 \text { ), } \\
\text { IKDC normal, } 1 \text { pt had knee } \\
\text { pain with stair climbing at final } \\
\text { follow-up }\end{array}$ & $\begin{array}{l}\text { MRI: } 50-100 \% \text { defect fill in } 6 \text { pts } \\
\text { (67\%), normal signals in } 4 \text { pts } \\
\text { at donor sites ( } 44 \%) \text {, effusion in } \\
1 \text { pt, no subchondral edema or } \\
\text { hypertrophic changes at donor } \\
\text { site }\end{array}$ \\
\hline Ovesen & No & - & No pain & - \\
\hline Nishimura & No & $\begin{array}{l}\text { No effusion at } 3 \text { months; } 80 \% \\
\text { muscle strength at } 6 \text { months, } \\
11 \text { pts regained strength at } \\
1 \text { year }\end{array}$ & $\begin{array}{l}\text { Lysholm } 100 \text { at } 6 \text { months; Visual } \\
\text { Analog Scale } 0 \text { at } 3 \text { months; } \\
100 \% \text { return to sports without } \\
\text { any donor knee disturbances }\end{array}$ & $\begin{array}{l}\text { Radiographs: absence of osteoar- } \\
\text { thritis at } 2 \text { years }\end{array}$ \\
\hline Kosaka & No & - & $\begin{array}{l}\text { 'None of the donor knees which } \\
\text { were removed of osteocartilagi- } \\
\text { nous tissues experienced nega- } \\
\text { tive effects' }\end{array}$ & - \\
\hline Maruyama & No & Full range of motion & $\begin{array}{l}\text { Lysholm } 99.8 ; 1 \text { pt had mild ante- } \\
\text { rior knee pain during exercise }\end{array}$ & - \\
\hline Weigelt & No & - & $\begin{array}{l}\text { Lysholm } 90.9 ; 7 \text { patients occa- } \\
\text { sional pain during lifting, } 1 \\
\text { locking sensations }\end{array}$ & - \\
\hline Lyons & No & - & $\begin{array}{l}\text { 'No complaints regarding the } \\
\text { donor knee at final follow-up' }\end{array}$ & - \\
\hline \multicolumn{5}{|c|}{ Rib-to-elbow osteochondral autologous transplantation $(N=62)$} \\
\hline Sato & No & - & $\begin{array}{l}\text { 2-3 days pain postoperatively; } \\
\text { no complaints during athletic } \\
\text { activities }\end{array}$ & - \\
\hline Shimada & $\begin{array}{l}\text { Pneumothorax, } \\
\text { resolved after tube } \\
\text { insertion }\end{array}$ & Hard scar tissue & Few days pain postoperatively & $\begin{array}{l}\text { Radiographs: subperiostal bone } \\
\text { formation in some pts }\end{array}$ \\
\hline Nishinaka & No & - & No pain or symptoms & - \\
\hline
\end{tabular}

IKDC International Knee Documentation Committee, MRI magnetic resonance imaging, pt patient

that were harvested $[1,2,25,27]$. Two included studies focused on donor-site effects in particular [9, 21]. Despite encouraging clinical results reported by Iwasaki et al., MRI evaluation revealed alterations in signal intensity in $89 \%$ of donor sites, suggesting fibrous filling of donor holes [9]. Long-term follow-up is needed to see if these changes in signal intensity are permanent and clinically meaningful. Nishimura et al. found a delay in recovery of quadriceps muscle strength [21]. This indicates that even if symptoms may resolve quickly after harvesting, the donor knee is at risk for injury due to muscle weakness within the first year. Three studies attempted to prevent postoperative bleeding by filling donor tunnels $[9,15,21]$. As included studies were limited by small case series, potential beneficial effects remain unclear. Favorable results have been reported using synthetic implants in repair of knee OCD [4, 6], although literature lacks large sample comparison studies.
Three studies that were included in this review harvested grafts from either the 5th or 6th costal-osteochondral junction to repair capitellar OCD [22, 28, 30]. Although hard scar tissue was detected in palpation, radiographs showed new subperiostal bone formation and no long-term symptoms were observed [30]. However, harvesting grafts from the rib area is a technically demanding procedure that has been described by only a few studies. Most surgeons who perform capitellar OATS are more familiar with knee anatomy rather than rib anatomy. Moreover, risk for devastating donor-site morbidity remains as harvesting may be complicated by a pneumothorax due to close proximity to the costal pleura, which may lead to a prolonged hospital stay [30]. If familiar with this technique, this may be an option in the treatment of large capitellar OCDs $(>15 \mathrm{~mm})$. As large lesions usually require multiple cylindrical grafts, one may want to avoid the risk for donor-site morbidity of the knee. 


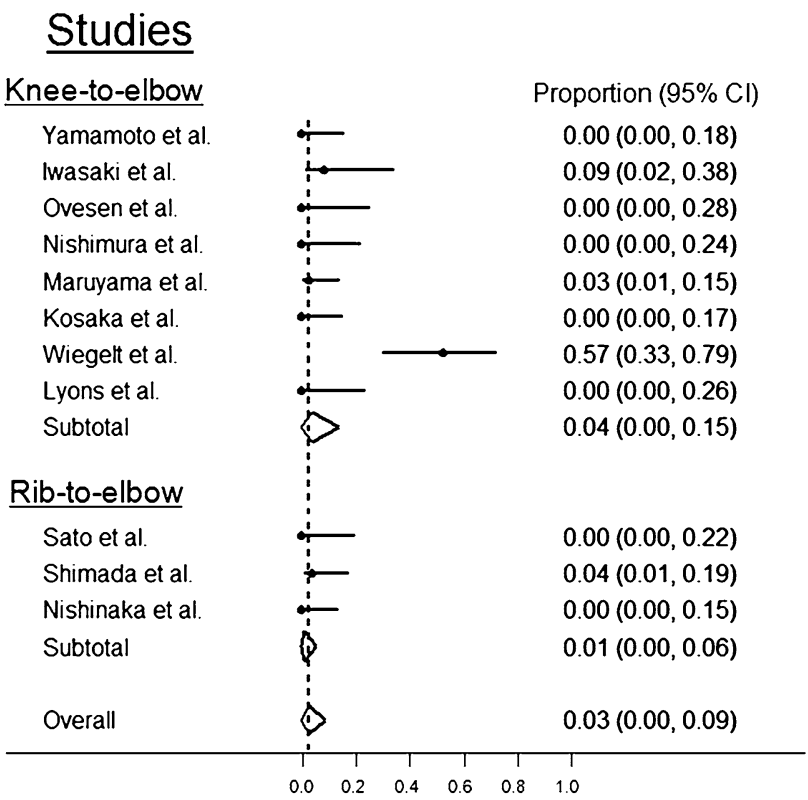

Fig. 2 Forest plot analysis demonstrating donor-site morbidity proportions after capitellar osteochondral autologous transplantation. The proportion of donor-site morbidity in the knee-to-elbow group was 0.04 (95\% CI $0.0-0.15)$, and the proportion in the rib-to-elbow group was 0.01 (95\% CI 0.0-0.06). There was no difference between harvest techniques in terms of proportion of donor-site morbidity (n.s.)

Using the IHE scale to evaluate the methodological quality of included studies [5, 20], the estimated potential risk of bias ranged from low to high, with the majority of studies found to be of moderate risk of bias ( 9 of 11). Studies scored the lowest on criteria related to outcome measures, as well as on the fact that cases were collected in a single center in each study. Therefore, the findings of this systematic review should be interpreted by taking into account some limitations. First, a major limitation is the incomplete reporting regarding outcomes related to the donor site. As physical examination or imaging was rarely thoroughly reported, studies lack objective assessment of donor-site effects. Additionally, subjective assessment of knee function by means of patient reported outcome measures was only performed in four of eight studies (Lysholm score) [9, 16, 21, 33]. In the remaining studies, no attempt was made to evaluate knee function, nor was physical examination thoroughly described $[11,15,24,35]$, as this was also the case in two rib-to-elbow studies $[22,28]$. Also, in none of the included studies, either subjective or objective preoperative assessment of the donor site was reported. As data were obtained from studies that evaluated donor-site effects in varying degrees, we hypothesized that donorsite morbidity may be substantially underreported in this population. Also, due to incomplete reporting, we were unable to investigate associations between morbidity and harvest characteristics including donor-site location and the size or number of grafts. Second, included studies are limited by case series with small numbers of patients because capitellar OCD is a rare condition in the general population, and capitellar OATS is a relatively new procedure. Third, after pooling the data of included studies, we found no significant difference between the proportions of donor-site morbidity for the knee-to-elbow group and the rib-to-elbow group $(p>0.05)$. One may argue whether it is valid to combine study data because of between-study variance; however, we attempted to alleviate statistical heterogeneity with the use of a random effects model. This model has been used previously in systematic reviews who pooled data from case series studies $[19,34]$.

Future studies should comprehensively evaluate effects related to the donor site. Patient's symptoms and physical examination should be reported for each patient. Additionally, the use of a patient reported outcome measure to assess knee function should be a routine part of clinical evaluation, both preoperatively and postoperatively. Radiographs should be performed to evaluate potential progression to osteoarthritis at 1 year and may be performed in cases in which donor fillers were used. MRI evaluation should, because of cost-effectiveness reasons, only be ordered in case of persistent symptoms. Besides the evaluation of donor-site effects, harvest characteristics should be reported in great detail, such as donor location, number of grafts, graft diameter, and depth. Also, alternative harvest methods should be investigated to have no longer the need to violate the integrity of an asymptomatic knee or rib in an adolescent athlete.

The findings of the present investigation demonstrate a considerable risk for donor-site morbidity following capitellar OATS. Although good-to-excellent results related to the elbow have been reported after capitellar OATS, surgeons should be aware of the risk for donor-site morbidity and patients should be counseled about this issue. Knowing the overall risk for donor-site morbidity is also relevant in surgical decision making. Taking this into consideration, surgeons could consider other resurfacing techniques such as allografting or autologous chondrocyte transplantation.

\section{Conclusions}

Osteochondral autologous transplantation in the treatment of capitellar osteochondritis dissecans may lead to donor-site morbidity in a considerable group of patients, either after harvesting from the femoral condyle (7.8\%) or costal-osteochondral junction (1.6\%). 


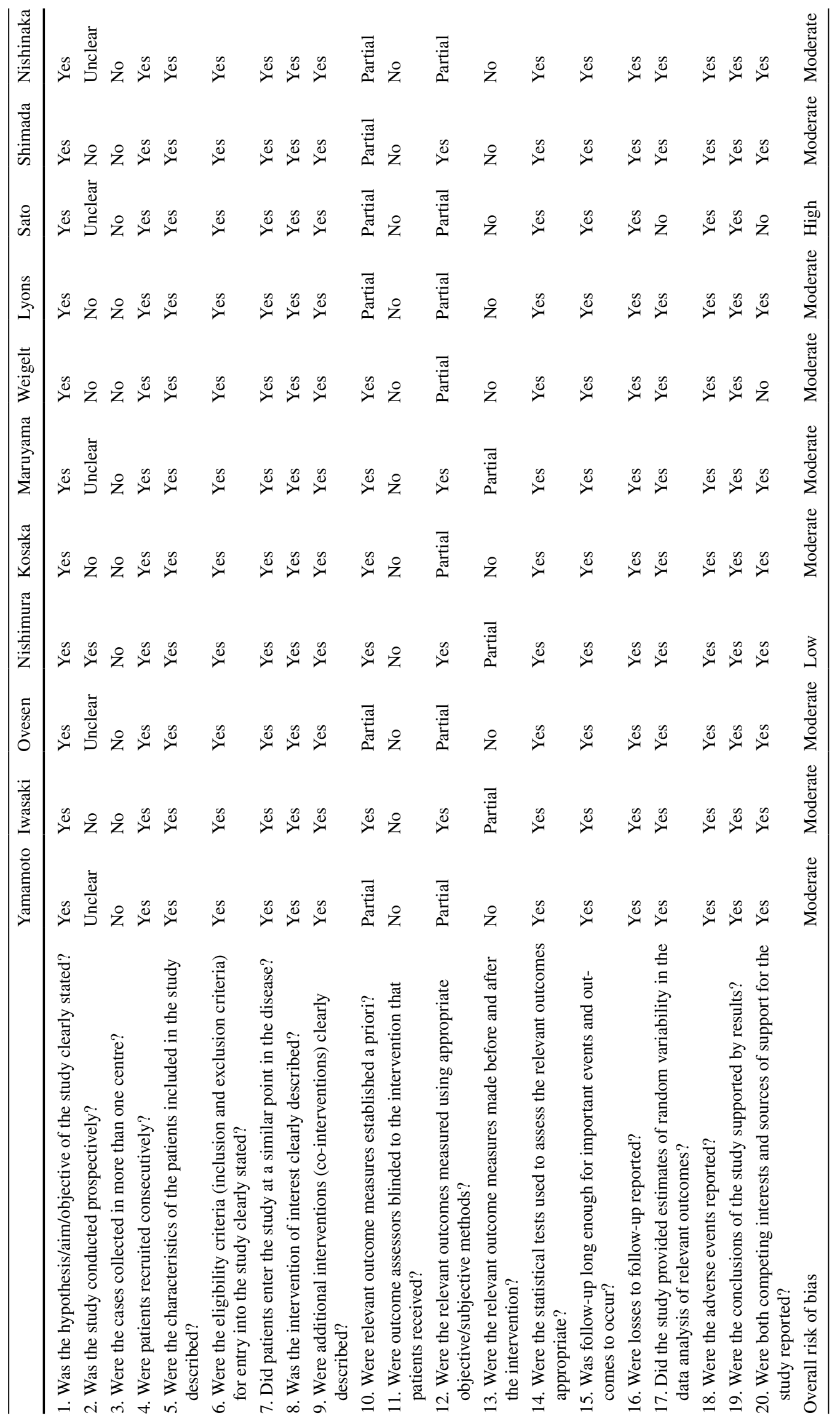


Acknowledgements The authors would like to thank Roos Steenhuis, medical librarian of the Onze Lieve Vrouwe Gasthuis, for the assistance in performing the literature search.

\section{Compliance with ethical standards}

Conflict of interest R. Bexkens, P.T. Ogink, J.N. Doornberg, G.M.M.J. Kerkhoffs, D. Eygendaal, L.S. Oh, and M.P.J. van den Bekerom declare that they have no conflict of interest.

Funding There was no outside funding or grants received that assisted in this study.

IRB/medical ethics committee Review was not needed for this study since it is a systematic review.

\section{Disclaimers None.}

Open Access This article is distributed under the terms of the Creative Commons Attribution 4.0 International License (http:// creativecommons.org/licenses/by/4.0/), which permits unrestricted use, distribution, and reproduction in any medium, provided you give appropriate credit to the original author(s) and the source, provide a link to the Creative Commons license, and indicate if changes were made.

\section{References}

1. Al-Shaikh RA, Chou LB, Mann JA, Dreeben SM, Prieskorn D (2002) Autologous osteochondral grafting for talar cartilage defects. Foot Ankle Int 23:381-389

2. Andrade R, Vasta S, Pereira R, Pereira H, Papalia R, Karahan M, Oliveira JM, Reis RL, Espregueira-Mendes J (2016) Knee donor-site morbidity after mosaicplasty - a systematic review. J Exp Orthop 3:31

3. Baker CL 3rd, Romeo AA, Baker CL Jr (2010) Osteochondritis dissecans of the capitellum. Am J Sports Med 38:1917-1928

4. Feczko P, Hangody L, Varga J, Bartha L, Dioszegi Z, Bodo G, Kendik Z, Modis L (2003) Experimental results of donor site filling for autologous osteochondral mosaicplasty. Arthroscopy 19:755-761

5. Guo B, Moga C, Harstall C, Schopflocher D (2016) A principal component analysis is conducted for a case series quality appraisal checklist. J Clin Epidemiol 69:199-207. e192

6. Hangody L, Bartha L, Hamann D, Pieper J, Peters F, Riesle J, Vajda A, Novak PK, Hangody LR, Vasarhelyi G, Bodo L, Van Blitterswijk C, De Wijn J, Kenyeres A, Modis L, Balo E (2013) A clinical feasibility study to evaluate the safety and efficacy of PEOT/PBT implants for human donor site filling during mosaicplasty. Eur J Orthop Surg Traumatol 23:81-91

7. Harada M, Ogino T, Takahara M, Ishigaki D, Kashiwa H, Kanauchi Y (2002) Fragment fixation with a bone graft and dynamic staples for osteochondritis dissecans of the humeral capitellum. J Shoulder Elb Surg 11:368-372

8. Iwasaki N, Kato H, Ishikawa J, Masuko T, Funakoshi T, Minami A (2009) Autologous osteochondral mosaicplasty for osteochondritis dissecans of the elbow in teenage athletes. J Bone Joint Surg Am 91:2359-2366

9. Iwasaki N, Kato H, Kamishima T, Suenaga N, Minami A (2007) Donor site evaluation after autologous osteochondral mosaicplasty for cartilaginous lesions of the elbow joint. Am J Sports Med 35:2096-2100

10. Koehler SM, Walsh A, Lovy AJ, Pruzansky JS, Shukla DR, Hausman MR (2015) Outcomes of arthroscopic treatment of osteochondritis dissecans of the capitellum and description of the technique. J Shoulder Elbow Surg 24:1607-1612

11. Kosaka M, Nakase J, Takahashi R, Toratani T, Ohashi Y, Kitaoka K, Tsuchiya H (2013) Outcomes and failure factors in surgical treatment for osteochondritis dissecans of the capitellum. J Pediatr Orthop 33:719-724

12. LaPrade RF, Botker JC (2004) Donor-site morbidity after osteochondral autograft transfer procedures. Arthroscopy 20:e69-e73

13. Lewine EB, Miller PE, Micheli LJ, Waters PM, Bae DS (2015) Early Results of Drilling and/or Microfracture for Grade IV Osteochondritis Dissecans of the Capitellum. J Pediatr Orthop 36:803-809

14. Liberati A, Altman DG, Tetzlaff J, Mulrow C, Gotzsche PC, Ioannidis JP, Clarke M, Devereaux PJ, Kleijnen J, Moher D (2009) The PRISMA statement for reporting systematic reviews and meta-analyses of studies that evaluate health care interventions: explanation and elaboration. Ann Intern Med 151:W65-W94

15. Lyons ML, Werner BC, Gluck JS, Freilich AM, Dacus AR, Diduch DR, Chhabra AB (2015) Osteochondral autograft plug transfer for treatment of osteochondritis dissecans of the capitellum in adolescent athletes. J Shoulder Elb Surg 24:1098-1105

16. Maruyama M, Takahara M, Harada M, Satake H, Takagi M (2014) Outcomes of an open autologous osteochondral plug graft for capitellar osteochondritis dissecans: time to return to sports. Am J Sports Med 42:2122-2127

17. Matsuura T, Kashiwaguchi S, Iwase T, Takeda Y, Yasui N (2008) Conservative treatment for osteochondrosis of the humeral capitellum. Am J Sports Med 36:868-872

18. Mihara K, Tsutsui H, Nishinaka N, Yamaguchi K (2009) Nonoperative treatment for osteochondritis dissecans of the capitellum. Am J Sports Med 37:298-304

19. Miller JJ (1978) The inverse of the Freeman-Tukey double arcsine transformation. Am Stat 32:138-138

20. Moga C, Guo B, Schopflocher D, Harstall C (2012) Development of a quality appraisal tool for case series studies using a modified Delphi technique. Institute of Health Economics, Edmonton AB

21. Nishimura A, Morita A, Fukuda A, Kato K, Sudo A (2011) Functional recovery of the donor knee after autologous osteochondral transplantation for capitellar osteochondritis dissecans. Am J Sports Med 39:838-842

22. Nishinaka $N$, Tsutsui $H$, Yamaguchi $K$, Uehara $T$, Nagai $S$, Atsumi T (2014) Costal osteochondral autograft for reconstruction of advanced-stage osteochondritis dissecans of the capitellum. J Shoulder Elb Surg 23:1888-1897

23. Nissen CW (2014) Osteochondritis dissecans of the elbow. Clin Sports Med 33:251-265

24. Ovesen J, Olsen BS, Johannsen HV (2011) The clinical outcomes of mosaicplasty in the treatment of osteochondritis dissecans of the distal humeral capitellum of young athletes. J Shoulder Elb Surg 20:813-818

25. Paul J, Sagstetter A, Kriner M, Imhoff AB, Spang J, Hinterwimmer S (2009) Donor-site morbidity after osteochondral autologous transplantation for lesions of the talus. J Bone Joint Surg Am 91:1683-1688

26. Rahusen FT, Brinkman JM, Eygendaal D (2006) Results of arthroscopic debridement for osteochondritis dissecans of the elbow. Br J Sports Med 40:966-969

27. Reddy S, Pedowitz DI, Parekh SG, Sennett BJ, Okereke E (2007) The morbidity associated with osteochondral harvest from 
asymptomatic knees for the treatment of osteochondral lesions of the talus. Am J Sports Med 35:80-85

28. Sato K, Nakamura T, Toyama Y, Ikegami H (2008) Costal osteochondral grafts for osteochondritis dissecans of the capitulum humeri. Tech Hand Up Extrem Surg 12:85-91

29. Schoch B, Wolf BR (2010) Osteochondritis dissecans of the capitellum: minimum 1-year follow-up after arthroscopic debridement. Arthroscopy 26:1469-1473

30. Shimada K, Tanaka H, Matsumoto T, Miyake J, Higuchi H, Gamo K, Fuji T (2012) Cylindrical costal osteochondral autograft for reconstruction of large defects of the capitellum due to osteochondritis dissecans. J Bone Joint Surg Am 94:992-1002

31. Takeba J, Takahashi T, Watanabe S, Imai H, Kikuchi S, Umakoshi K, Matsumoto H, Ohshita M, Miura H, Aibiki M (2015) Short-term clinical results of arthroscopic osteochondral fixation for elbow osteochondritis dissecans in teenaged baseball players. J Shoulder Elb Surg 24:1749-1756
32. van Bergen CJ, van den Ende KI, Ten Brinke B, Eygendaal D (2016) Osteochondritis dissecans of the capitellum in adolescents. World J Orthop 7:102-108

33. Weigelt L, Siebenlist S, Hensler D, Imhoff AB, Vogt S (2015) Treatment of osteochondral lesions in the elbow: results after autologous osteochondral transplantation. Arch Orthop Trauma Surg 135:627-634

34. Westermann RW, Hancock KJ, Buckwalter JA, Kopp B, Glass N, Wolf BR (2016) Return to sport after operative management of osteochondritis dissecans of the capitellum: a systematic review and meta-analysis. Orthop J Sports Med 4:2325967116654651

35. Yamamoto Y, Ishibashi Y, Tsuda E, Sato H, Toh S (2006) Osteochondral autograft transplantation for osteochondritis dissecans of the elbow in juvenile baseball players: minimum 2-year follow-up. Am J Sports Med 34:714-720 